\title{
Typizität als Strukturprinzip des Privatrechts
}

\author{
Ein Beitrag zur Standardisierung übertragbarer Güter
}

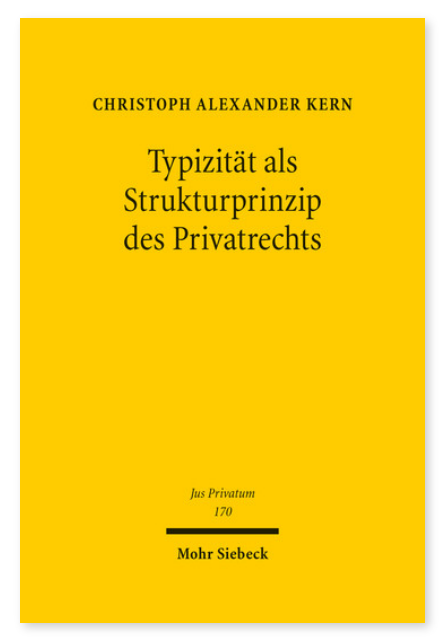

2013. XLI, 614 Seiten. JusPriv 170

ISBN 978-3-16-152097-6

DOI 10.1628/978-3-16-152097-6

eBook PDF 139,00€

ISBN 978-3-16-151724-2

Leinen $139,00 €$
Sachen und die an innen bestehenden Rechte, aber auch Wertpapiere sind übertragbare Güter par excellence. Im Sachenrecht begegnen uns dabei heute weltweit mehr oder weniger streng standardisierte Typen bestimmter Rechte. Im Wertpapierrecht lässt sich bei den Wertpapieren des Kredit- und Zahlungsverkehrs sowie den Wertpapieren des Warenverkehrs eine ähnliche Entwicklung hin zu gesteigerter Typizität beobachten. Nicht in dieselbe Richtung verlief in den letzten Jahrzehnten demgegenüber die Entwicklung der Wertpapiere des Kapitalmarkts. Dieser Befund lässt sich dadurch erklären, dass die Wertpapiere des Kapitalmarkts versuchen, die positiven Wirkungen von Typizität mit alternativen Mechanismen zu erreichen. Allerdings scheint dies nur unzureichend zu gelingen, weshalb sich eine behutsame Steigerung von Typizität auch bei den Kapitalmarktpapieren empfiehlt.

Christoph A. Kern ist Professor für Bürgerliches Recht und Prozessrecht an der Universität Heidelberg. https://orcid.org/0000-0001-7483-5471
Jetzt bestellen:

https://mohrsiebeck.com/buch/typizitaet-als-strukturprinzip-des-privatrechts-9783161520976?no_cache=1 order@mohrsiebeck.com

Telefon: $+49(0) 7071-923-17$

Telefax: $+49(0) 7071-51104$ 